\section{Inclusion and the Right to Access to Regular Classes for Students with Disabilities}

\author{
Audri Sandoval-Gomeza, Meghan Cosier ${ }^{b}$, Donald N. Cardinalc
}

Ches

$\begin{array}{ll}\text { Received: } & 9 \text { September } 2019 \\ \text { Revised: } \quad 20 \text { October } 2019 \\ \text { Accepted: } \quad 12 \text { December } 2019 \\ \text { ISSN: 1307-9298 } \\ \text { Copyright ( } \text { IEJEE } \\ \text { www.iejee.com }\end{array}$

DOI: $10.26822 /$ iejee.2020358216

\section{Introduction}

In the past decades many countries have made progress toward increasing access to quality education for students with disabilities, yet The World Bank (2019) estimates that 85\% of children with disabilities continue to lack access to any schooling. The right to access for K-12 students with disabilities has been recognized globally and locally in many countries across the world (United Nations Education, Scientific and Cultural Organization [UNESCO], 2016), with each country making decisions on how to increase access to regular classes based on local contexts and needs. The result is the development of innovative policy and practice that support access to regular classes. These innovative policies and practices highlight the promise of access, equity, and inclusion for students with disabilities. We acknowledge that "inclusion" is not an end, but rather something we are all working toward. We agree with the UNESCO (2016) definition of inclusive education which states, "a process of addressing and responding to the diversity of needs of all learners through increasing participation in learning, cultures and communities, and reducing exclusion from education and from within education" (p. 86). Furthermore, we support the notion that, "Inclusion and equity in and through education is the cornerstone of a transformative education agenda" (p. 8). Collectively sharing our work and communicating and collaborating in regions across the world helps us learn from each other and enact such a transformative agenda. By doing this, we can focus on increasing access and equity for some of the most marginalized students including students in poverty, women and girls, and students with disabilities. In an effort to promote such communication and collaboration to enact a transformative agenda, the collection of articles in this special issue allows us to highlight the work of increasing equity and access in a number of areas including transition, students with complex support needs, students with Autism, collaboration, and policy.

When considering best practices and policy for elementary age individuals with disabilities, accounting for the longterm outcomes for these individuals is essential; our focus on the short-term must surely be connected to the intended long-term outcomes (Ryndak, Alper, Hughes, \& McDonnell, 2012). In "Her Voice: Engaging Girls with Disabilities in STEM Careers," Griffiths, Miles Nash, Maupin and Mathur propose a framework for policy and practice that promotes concrete ways of thinking about shoring up the pipeline for girls with disabilities for careers in STEM.
In considering access to education and transition to employment, we must include students with more complex or extensive support needs (ESN) in our discussions. Both Hanreddy and Östlund and Cosier, Sandoval-Gomez, and Cardinal present perspectives on access and inclusion for populations of students with disabilities considered to have complex or extensive support needs. Hanreddy and Östlund provide a discussion around the potential impact of "alternate curricula" on access for students with disabilities in the US and Sweden, while Cosier, Sandoval-Gomez, and Cardinal demonstrate considerations for identifying factors associated with placement and access for students with ESN. Both articles represent the necessary inclusion of students with ESN in discussions around access and inclusion.

While Hanreddy and Östlund focus on the US and Sweden, articles by Nguyen, Villa, Le, Thousand and Pham focus on access and inclusion in Vietnam more broadly, with Tran, Pham, Mai, Le and Nguyen focusing on individuals with Autism labels. Both articles lend an important and necessary contribution to the field in terms of how developing countries are supporting access and inclusion for all students.

While many articles focus on specific areas of inclusion and access, Taub and Foster widen the lens to look at international policy and the implications of policy on the inclusion of students with disabilities. Taub and Foster attempt to reduce the barriers to cross-cultural research of inclusive practices by investigating the use of terms inclusion and intellectual disability across six countries to potentially improve collaboration and facilitate the generalization of practices.

Lastly, Solone, Thornton, Chiappe, Perez, Rearick, \& Falvey provide an overview of best practices on creating a collaborative culture for inclusive education. The authors provide us with a reminder of the importance of collaboration across multiple entities in order to develop sustainable practices of inclusive education.

The articles included in this special issue point to the multi-faceted aspects of inclusive education that must be considered as we support the movement to equity and access for all students. We acknowledge that the articles do not represent all perspectives or all areas of the world. There are many scholars and practitioners working in inclusive education all around the world, and these perspectives are valued; we hope to see future articles represent work in areas not included in these articles, including the South Asia, Australia, and the Global South. 


\section{References}

Ryndak, D., Alper, S., Hughes, C., \& McDonnell, J. (2012). Documenting impact of educational contexts on long-term outcomes for students with significant disabilities. Education and Training in Autism and Developmental Disabilities, 47(2),127-138.

The World Bank. (2019, April 12). Inclusive education initiative: Transforming education for children with disabilities. Retrieved from https://www.worldbank.org/en/topic/socialdevelopment/brief/inclusive-education-initiative-transforming-education-for-children-with-disabilities

United Nations Education, Scientific and Cultural Organization [UNESCO]. (2016). Education 2030: Incheon Declaration and Framework for Action for the implementation of Sustainable Development Goal 4: Ensure inclusive and equitable quality education and promote lifelong learning opportunities for all. (Call number 37.018.8 EDU [452]). Retrieved from https:// unesdoc.unesco.org/ark:/48223/pf0000245656 